\title{
Investigating Antihypertensive, Angiotensin-I Converting Enzyme (ACE)- Inhibitory Activity of Soldier Bean Protein Hydrolysates
}

${ }^{1}$ Heather-Ann Burrell, ${ }^{1}$ Dr. Marcia English, ${ }^{2}$ Dr. Alejandro Cohen

${ }^{1}$ St. Francis Xavier University, Antigonish, NS; ${ }^{2}$ Dalhousie University, Halifax, NS

\section{INTRODUCTION}

Hypertension affects 7.2 million Canadians and is a leading risk factor for premature death, stroke and heart disease ${ }^{1}$. However, hypertension can be managed and modified via dietary interventions. High protein functional foods such as milk and soybeans have demonstrated the ability to lower blood pressure due to their antihypertensive bioactive peptides ${ }^{2}$.

One way that bioactive peptides can effect hypertension is by inhibiting Angiotensin-1 Converting Enzyme (ACE). ACE hydrolyses angiotensin-I into a powerful vasoconstrictor, angiotensin II, which in turn increases blood pressure (Figure 1). Therefore, peptides that inhibit ACE have the potential to reduce blood pressure by decreasing the production of angiotensin II. Although several research studies have shown that red lentils and chickpeas contain bioactive peptides with ACE-inhibitory properties, to date, no studies have been conducted to determine if Nova Scotian soldier bean (SB) proteins contain peptides with ACE-inhibitory properties ${ }^{3}$.

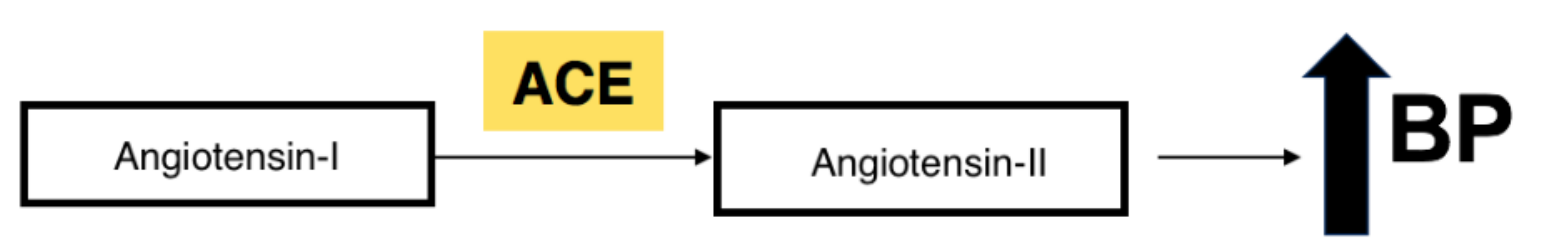

Figure 1. The relationship between ACE and blood pressure.

\section{AIM OF STUDY}

The aim of the present study was to determine if trypsin hydrolysis of SB proteins would generate peptides with ACE-inhibitory properties.

\section{METHODS}

SB protein isolates were hydrolysed with trypsin over a two-hour period and aliquots were obtained at $30 \mathrm{~min}$ intervals (Figure 2). Two enzyme: substrate (E:S) ratios were used (1:100 and 1:250), and the degree of hydrolysis (DH) was determined by the 2,4,6Trinitrobenzenesulfonic acid (TNBS) assay. ACE-inhibitory activity was also measured using the hippuryl-His-Leu (HHL) substrate method. For these studies, a commercial pea protein, Propulse ${ }^{\mathrm{TM}}$ was used as a control.

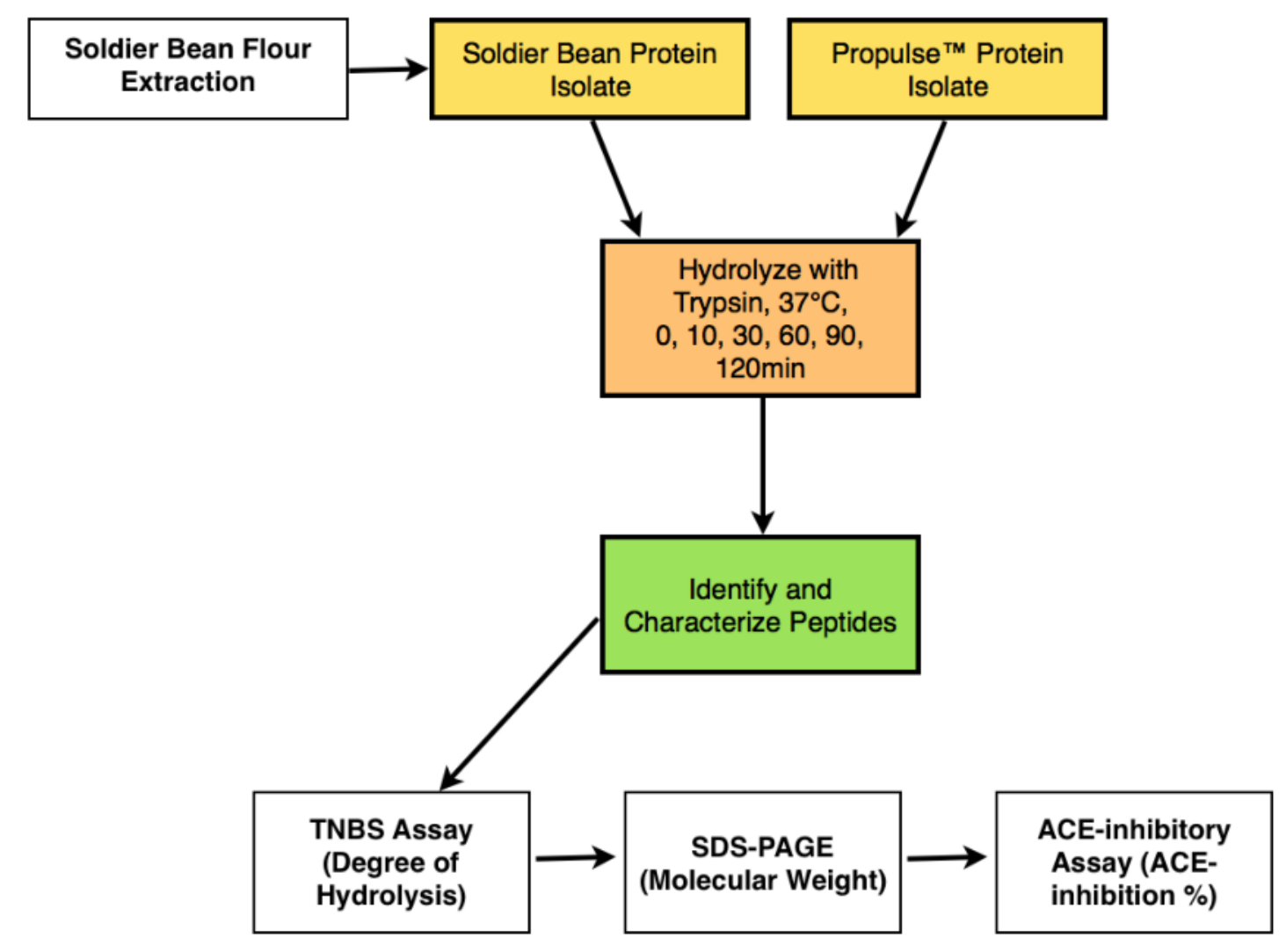

Figure 2. Overview of experimental design.

\section{RESULTS}

The DH of Propulse ${ }^{\mathrm{TM}}$ and SB Increases Over Time

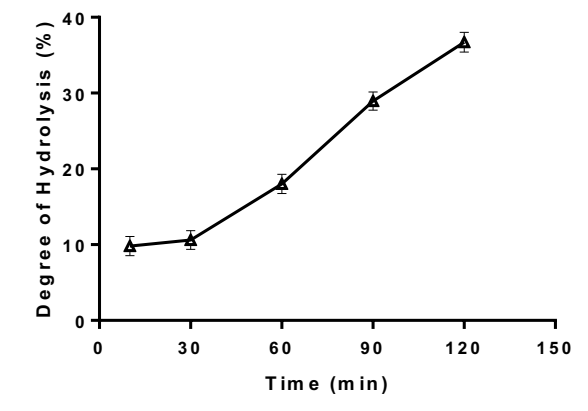

Figure 3. DH for Propulse ${ }^{\mathrm{TM}}$

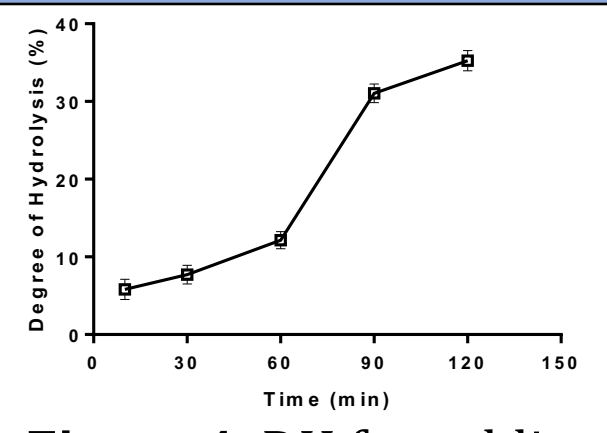

Figure 4. DH for soldier bean. SB Exhibits ACE-Inhibitory Properties

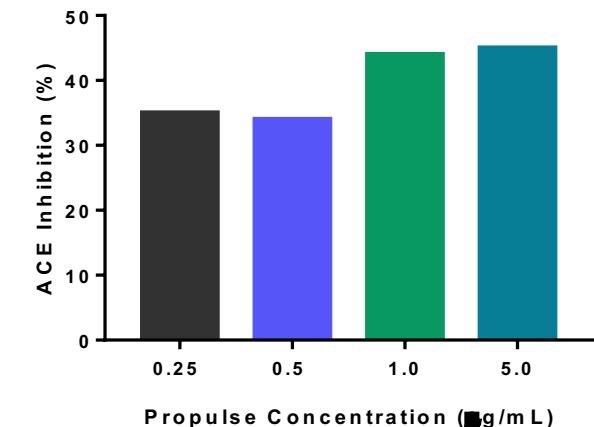

Figure 5. ACE-inhibitory activity of Propulse $^{\mathrm{TM}}$ in a 1:100 E/S ratio.

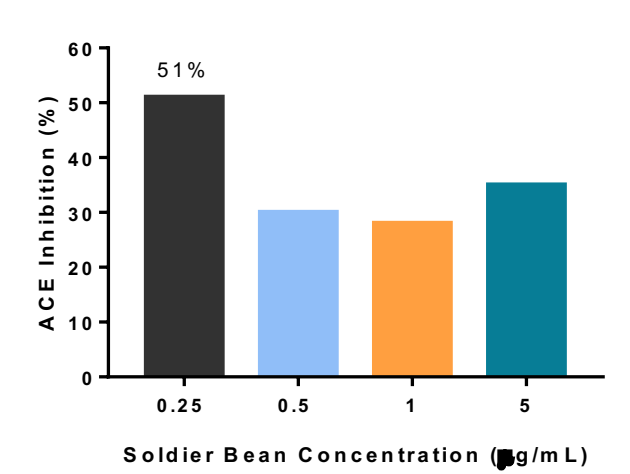

Figure 7. ACE-inhibitory activity of $\mathrm{SB}$ in a 1:100 E/S ratio

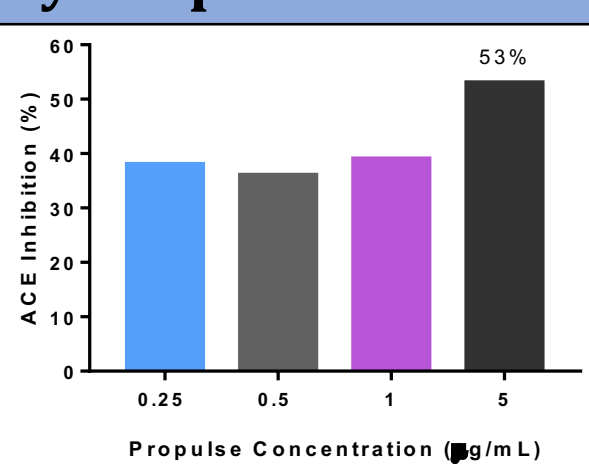

Figure 6. ACE-inhibitory activity of Propulse $^{\mathrm{TM}}$ in a 1:250 E/S ratio.

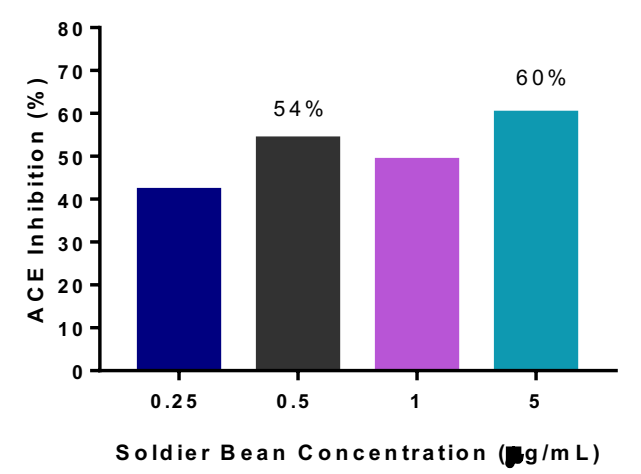

Figure 8. ACE-inhibitory activity of $\mathrm{SB}$ in a $1: 250 \mathrm{E} / \mathrm{S}$ ratio

\section{CONCLUSIONS}

SB peptides were found to inhibit ACE activity. At a 1:100 E/S ratio, $\mathrm{SB}$ peptides inhibited $\mathrm{ACE}$ at the lowest concentration of $0.25 \mu \mathrm{g} / \mathrm{mL}$. In the $1: 250 \mathrm{E} / \mathrm{S}$ ratio, SB peptides inhibited ACE at 0.5 and $5 \mu \mathrm{g} / \mathrm{mL}$ concentrations. This shows the need for future research to find the optimum E/S ratio for hydrolysing SB. Although preliminary, the findings from this study provide an important first-step in establishing evidence to further investigate Nova Scotian SB as potential candidates for antihypertensive activity. Further research is required to determine if the in vitro ACE-inhibitory effects of SB peptides are applicable in vivo. Dietetic research that continues to examine the antihypertensive abilities of pulses offers the potential to provide supportive evidence for dietary interventions used to combat the prevalence of hypertension in Canadian adults.

\section{ACKNOWLEDGEMENTS}

Special thanks to my second reader, Dr. Alejandro Cohen and my supervisor, Dr. Marcia English for their support and guidance. This study was made possible by a start-up research grant to M.E. from the StFX University. H.A.B. was a 2017 recipient of the Irving Undergraduate Research mentorship award.

\section{REFERENCES}

${ }^{1}$ Cloutier, L., Daskalopoulou, S. S., Padwal, R. S., Lamarre-Cliche, M., Bolli, P., McLean, D. ... \& Townsend, R. (2015). A new algorithm for the diagnosis of hypertension in Canada. Canadian Journal of Cardiology, 31(5), 620-630.

${ }^{2}$ Pan, S., Wang S., Jing, L., \& Yao D. (2006). Purification and characterization of a novel angiotensin-I converting enzyme (ACE)-inhibitory peptides derived from the enzymatic hydrolysate of Enteromorpha clathrata protein. Food Chemistry, 211, 423 430.

${ }^{3}$ Aluko, R. (2015). Antihypertensive peptides from food proteins. Annual Review of Food Science and Technology, 6, 235-262. 